Lustoza, A.C. '; Silva, S.B.'

Franco, M.B.'; Baudi, D.L.K.'; Werner, J. ${ }^{3}$; Sincero, P.C.'; Sprea, G. ${ }^{2}$; Champion, T. ${ }^{4} ;$ Silva, G.B. ${ }^{4}$

\section{1 - Otite externa associada a Demodex cati e Otodectys cynotis em felino}

\author{
1- Médica Veterinária contratada do Centro Veterinário Puppy Brasil, São Paulo-SP
}

Demodex cati apresenta um número reduzido de relatos em medicina veterinária, principalmente associado ao Otodectys cynotis. Este último tem uma prevalência estimada em $25 \%$ dos felinos saudáveis. $O D$. cati apresenta menor tamanho que o D. camis e algumas diferenças estruturais, o que torna improvável a transmissão entre espécies. Assim como nos cães, a demodicose generalizada em felinos está associada a quadros imunossupressivos como infecções por Fiv, Felv, complexo respiratório, diabetes melitus ou distúrbios hormonais; sendo que esta forma é mais comum em felinos idosos. A demodicose localizada ou ótica é mais comum em animais jovens, normalmente não está associada a outras doenças e aparenta ser auto limitante. A presença de D. cati foi relatada pela primeira vez em $1919 \mathrm{em}$ conduto auditivo externo, e o animal recebeu tratamento tópico apenas com ceruminoliticos. Um animal da espécie felina, Persa, fêmea de 4 meses de idade foi atendido em uma clínica privada com a queixa de prurido e excesso de secreção ótica. Ao exame clínico, o animal apresentava bom estado geral, vacinação ética atualizada e tinha sido adquirido recentemente pelo proprietário. Ao exame físico não houveram alterações significativas quanto a mucosas, temperatura corpórea, auscultação cardio-pulmonar, linfonodos e palpação abdominal; ao exame otoscópico, presença de grande quantidade de cerúmen enegrecido em porção externa e interna dos condutos, também foi observado um leve eritema. O cerúmen de ambos condutos foi avaliado ao microscópio óptico comum sem o auxilio de coloraçōes, onde foram encontradas formas adultas e ovos de Otodectys cynotis e Demodex cati. $\mathrm{O}$ animal foi submetido a um hemograma e teste sorológico para Fiv e Felv. Os resultados obitidos apresentaram-se dentro dos padrões da normalidade. O uso do amitraz a $0.025 \%$ é indicado na literatura para o tratamento da demodicose felina generalizada ou localizada, mesmo sabendo-se dos sérios efeitos colaterais. Neste caso, o animal recebeu instilação tópica de fipronil em ambos os condutos, seguido do uso de ceruminolitico duas vezes ao dia. Em três dias, ao retorno, o proprietário relatou melhora do prurido ótico, e ao exame otoscópico notou-se ainda leve eritema e grande quantidade de cerúmen enegrecido. Foi entào efetuado um segundo exame parasitológico de cerúmen ao microscópio óptico comum, onde foram observadas ainda formas adultas e ovos de Demodex cati. Foi recomendado continuar o uso do ceruminolítico, e uma nova aplicação de fipronil com intervalo de 7 dias da primeira. Após esta segunda aplicaçào o exame parasitológico passou a ser negativo e ao longo de uma semana o animal apresentou remissão completa dos sintomas.

\section{2 - Penfigóide bolhoso. Relato de caso}

1- MV, MS, Professora do Departamento de Medicina Veterinária da Universidade Federal do Paraná, Curitiba-PR

2- MV, Mestranda, Curso de Pós-Graduação em Ciencias Veterinária da Universidade Federal do Paraná, Curitiba-PR

3- MV, MS, Patologista da Universidade Federal do Paraná, Curitiba-PR

4- MV, Hospital Veterinário da Universidade Federal do Paraná, Curitiba-PR

O penfigóide bolhoso é uma doença auto-imune rara em cães, sem predileções por idade e sexo. Manifesta-se como uma dermatite vesicobolhosa e ulcerativa, acometendo a pele, junçōes mucocutâneas, mucosas e região plantar. As lesões incluem bolhas e vesículas transitórias, crostas, colaretes epidérmicos e ulceraçòes, sendo que a mucosa oral apresentase acometida na maioria dos casos. O diagnóstico diferencial inclui o pênfigo vulgar, lúpus eritematoso sistêmico, eritema multiforme, necrólise epidérmica tóxica, candidiase, linfoma epiteliotrópico e várias outras dermatoses ulcerativas caninas. $O$ diagnóstico definitivo baseia- 